\title{
Penerapan Metode TOPSIS untuk Seleksi Penerima Beasiswa (Studi Kasus: SMAN 2 Tebing Tinggi Timur)
}

\author{
Uci Rahmalisa ${ }^{1}$, dan Muhardi ${ }^{2}$ \\ Sistem Informasi, STMIK Hang Tuah Pekanbaru, Jl. Mustafa Sari No. 5, Pekanbaru \\ E-mail: $\left\{{ }^{1}\right.$ ucirahmalisa $89,{ }^{2}$ muhardi.yudie $\}$ gmail.com
}

\begin{abstract}
Government efforts to overcome the high cost of education by providing tuition assistance to underprivileged students in funding education, called scholarships. This scholarship is aimed at students who are economically disadvantaged. Students must have certain criteria that will be assessed by the school in considering their eligibility as scholarship recipients. Therefore, it is necessary to have a decision support system which will be able to shorten the selection time and improve quality in determining scholarship acceptance. the decision support system used is TOPSIS based on predetermined criteria. By using this method, it will be able to produce objective decisions in determining scholarship receipts at Tebing Tinggi Timur 2 High School.
\end{abstract}

Keywords: Decision support system, TOPSIS, scholarship

\section{Pendahuluan}

Tingginya biaya untuk menyelesaikan pendidikan menjadi salah satu permasalahan pendidikan di Indonesia. Untuk mengatasi masalah tingginya biaya pendidikan di antaranya adalah berusaha memberikan bantuan biaya pendidikan kepada siswa kurang mampu dalam membiayai pendidikan. Untuk memperoleh beasiswa tersebut maka siswa harus memiliki beberapa persyaratan khusus yang akan menjadi tolok ukur penilaian oleh pihak sekolah dalam menetapkan kelayakannya sebagai penerima beasiswa. Adapun beberapa hal yang harus perhatikan dalam penyerahan beasiswa yaitu kapasitas penerima, persyaratan administrasi berupa berkas, kemampuan ekonomi serta kompetensi akademik yang sesuai dengan ketentuan masing-masing program beasiswa (Wijaya, 2015).

SMA N 2 Tebing Tinggi Timur merupakan salah satu lembaga pendidikan penyalur beasiswa masih menggunakan cara manual dalam proses seleksi karena belum ada penerapan metode yang sistematis dan objektif dalam pemilihan penerima beasiswa sehinga cenderung bersifat subjektif. Untuk menghindari penilaian secara subjektif dalam pemilihan penerima beasiswa tersebut, maka disarankan untuk menggunakan sebuah sistem pendukung keputusan dengan proses yang lebih objektif, sistematis, dan terkomputerisasi sehingga penerima beasiswa lebih tepat sasaran dengan kualifikasi terbaik.

Berdasarkan hal tersebut maka diperlukan aplikasi yang terkompterisasi dalam menetapkan penerima beasiswa melalui penyeleksian menggunakan metode TOPSIS. Metode ini memiliki beberapa kelebihan, yaitu konsepnya yang mudah di mengerti dan sederhana. Sistem pengambil keputusan penerima beasiswa ini dirancang agar dapat membantu pihak sekolah untuk menetapkan penerima beasiswa dengan cepat, tepat, efisien waktu, objektif sehingga dapat dengan cepat menghasilkan suatu keputusan dalam penyeleksian penerima beasiswa.

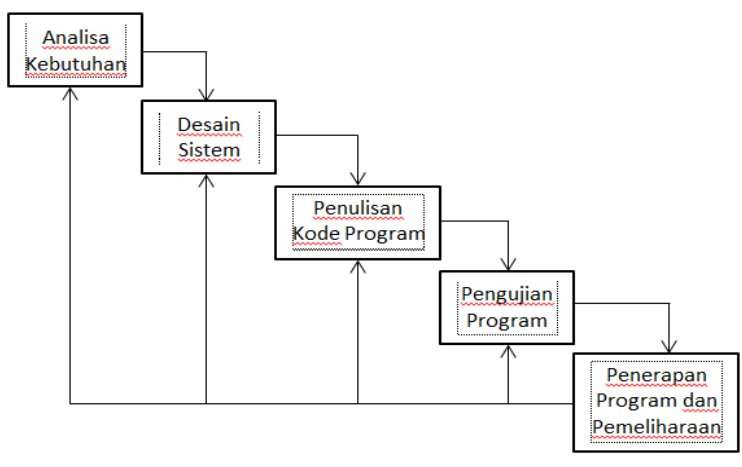

Gambar 1. Waterfall Model

\section{Metode Penelitian}

Dalam penelitian ini, metode yang diterapkan yaitu waterfall method. Adapun tahapan metode waterfall secara umum adalah 
melakukan analisa, desain sistem, coding program, pengujian program, penerapan dan pemeliharaan (Kadir, 2003) seperti pada Gambar 1.

Tahapan pada waterfall terdiri dari:

1. Analisa Kebutuhan

Pada tahap ini yang akan dilakukan yaitu mengumpulkan data yang dibutuhkan dalam proses penelitian dengan teknik wawancara, studi pustaka dan observasi. Adapun teknik pengumpulan data yang digunakan adalah observasi atau mendatangi langsung ke tempat penelitian serta wawancara, dimana yang menjadi objek yaitu kepala sekolah dan pihak yang terkait dalam penentuan seleksi penerima beasiswa tersebut. Dan tahapan ini berfungsi untuk untuk mempersiapkan pelaksanaan rancangan sistem untuk pemilihan beasiswa dengan metode TOPSIS.

2. Desain Sistem

Pada rancang sistem ini yang akan dibuat adalah rancangan database serta rancangan tabel, desain input dan desain output dari sistem yang akan dihasilkan nanti. Adapun dalam proses perancangan ini, secara garis besar merupakan hasil dari analisa kebutuhan yang telah dilakukan sebelumnya.

3. Penulisan Kode Program

Merupakan tahapan implementasi dari rancangan sistem yang telah dirancang sebelumnya kedalam coding program (bahasa yang dipahami oleh komputer). Pada sistem ini akan digunakan bahasa pemrograman PHP dengan database MySQL.

4. Uji Program

Tahapan setelah pengkodean adalah melakukan pengujian terhadap sistem. Sistem yang ada akan diuji kinerja dan keefektifannya sehingga akan didapatkan hasil apakah sistem berjalan dengan baik atau terdapat kelemahan sistem sehingga perlu dilakukan analisa ulang serta perbaikan terhadap aplikasi agar dapat berjalan lebih baik. Pengujian program pada penelitin ini akan dilakukan dengan menggunakan pengujian black box. Pada pengujian ini semua aktifitas sistem akan diuji apakah sudah berjalan sesuai yang diharapkan atau belum.

5. Penerapan Program dan Pemeliharaan Penerapan SPK penerima beasiswa ini akan dilakukan disekolah tersebut dan kemudian akan dilakukan sosialisasi dengan pihak terkait mengenai cara penggunaan sistem ini agar sistem siap untuk dioperasikan. Pemeliharaan perlu dilakukan agar sistem yang telah diterapkan dapat terus berjalan dengan baik dan melakukan perbaharuan pada sistem jika dirasa perlu.

\section{Pembahasan}

\section{Halaman Login ke Sistem}

Halaman login ini befungsi untuk keamanan sistem, sistem akan memanggil user dan password berdasarkan user yang telah dimasukkan di database.

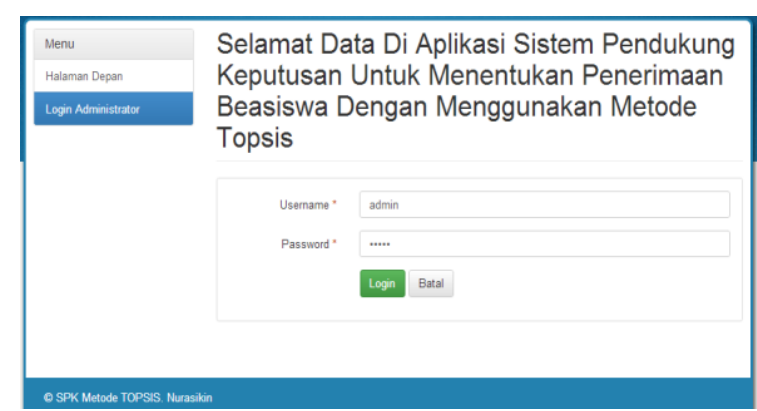

Gambar 2. Tampilan Halaman Login

Pada saat melakukan login, tampilan seperti gambar diatas akan terlihat ketika user melakukan login. Pada saat user memasukkan username dan password, sistem akan memvalidasi apakah login sudah benar atau belum, jika benar maka sistem akan melanjutkan masuk ke halaman berikutnya. Jika tidak valid, sistem akan memberikan notifikasi atau alert bahwa "username atau password yang anda inputkan salah"

\section{Halaman Home}

Ini merupakan tampilan awal untuk pimpinan dan admin setelah melakukan login.

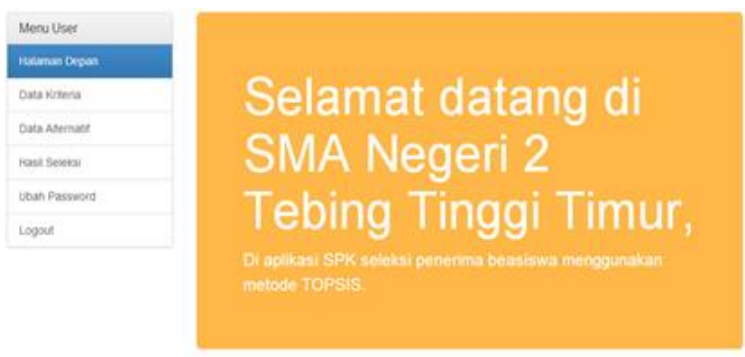

Gambar 3. Tampilan Halaman Menu Utama 
Setelah melakukan login, tampilan selamat datang ini akan dihadapkan kepada Admin dan Pimpinan, di mana menu-menu yang ada disesuaikan dengan login yang telah ditentukan.

\section{Tampilan Data Kriteria}

Halaman tampilan data kriteria ini adalah halaman yang diakses oleh admin untuk mengelola data pemilihan kriteria.

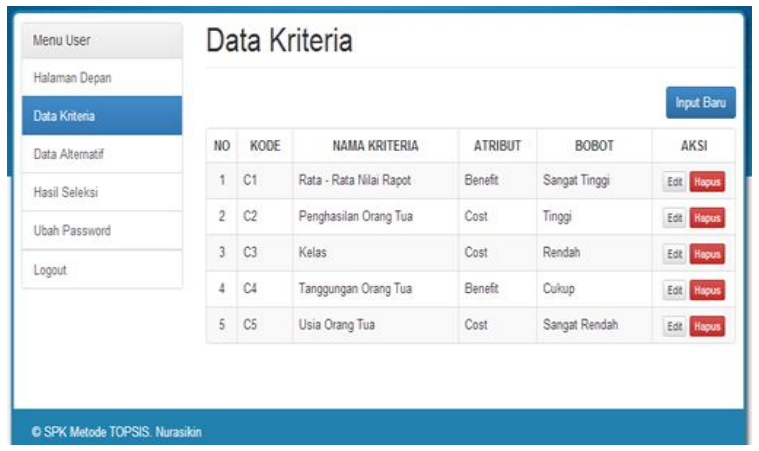

Gambar 4. Tampilan Halaman Data Nilai

Di halaman kriteria ini berupa tampilan data-data kriteria yang sudah dimasukkan kedalam sistem. Data kriteria yang dimaksud adalah:

1. $\mathrm{C} 1=$ Rata-rata Nilai Raport

2. $\mathrm{C} 2$ = Pendapatan Orang Tua

3. $\mathrm{C} 3=$ Kelas

4. $\mathrm{C} 4=$ Tanggungan Orang tua

5. C5 = Umur Orang Tua

Kriteria ini juga bisa ditambah atau dikurang disesuaikan dengan keperluan. Kriteria yang ada itu nantilah yang akan menjadi pertimbangan sistem dalam menentukan siswa yang berhak menerima beasiswa.

\section{Tampilan Input Data Kriteria}

Tampilan halaman input data kriteria ini adalah halaman yang diakses oleh admin untuk mengelola data-data kriteria. Pada tampilan ini, Admin dapat menambahkan kriteria apa saja yang nantinya akan digunakan dalam aplikasi ini nantinya, bisa dikatakan bahwa kriteria bersifat fleksibel sesuai dengan kebutuhan.

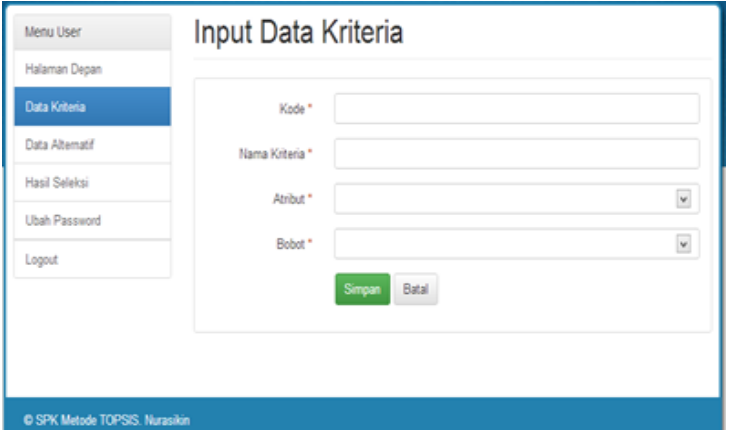

Gambar 5. Tampilan Input Data Kriteria

\section{Tampilan Data Alternatif}

Tampilan halaman data alternatif ini adalah halaman yang diakses oleh admin untuk mengelola pilihan data alternatif.

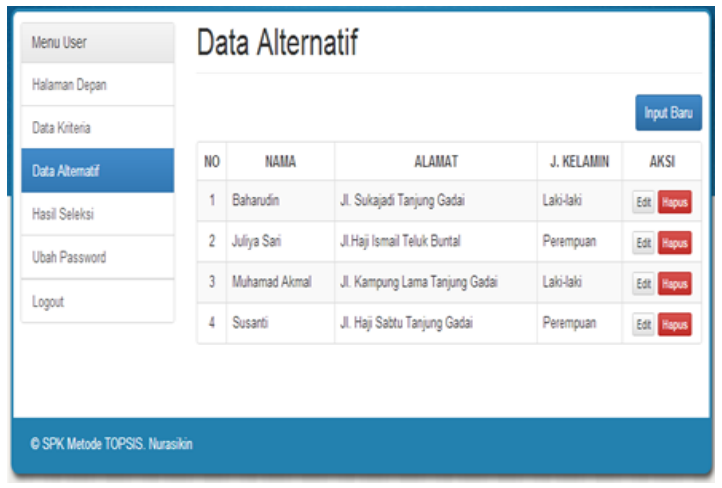

Gambar 6. Tampilan Halaman Data Alternatif

Pada tampilan ini, Admin mampu menghapus, mengedit dan menambah data yang menjadi alternatif pada sistem. Data alternatif bisa lebih dari 3 atau disesuaikan dengan kebutuhan pihak sekolah.

\section{Tampilan Input Data Alternatif}

Tampilan halaman input data alternatif ini adalah tampilan yang digunakan oleh admin untuk menambahkan data-data alternatif.

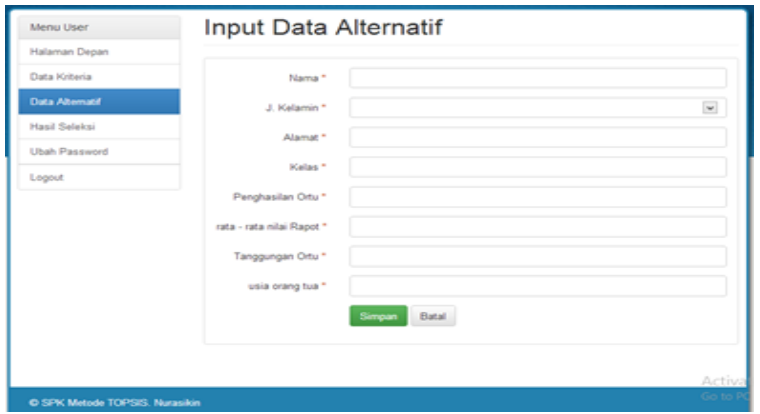

Gambar 7. Tampilan Halaman Input Data Alternatif 
Yang ada pada halaman input data alternatif ini berupa data-data alternatif yang belum dimasukkan ke dalam sistem (contohnya: nama, jenis kelamin, alamat, kelas, penghasilan orang tua, rata-rata nilai raport, tanggungan dan usia orang tua). Data alternatif yang diinputkan juga bisa sebanyak peserta yang akan mengikuti seleksi penerimaan beasiswa pada sekolah tersebut.

\section{Tampilan Hasil Data Seleksi}

Sebelum pembahasan mengenai tampilan hasil data seleksi, ada beberapa langkah penyelesaian yang menjadi perhatian, dalam metode TOPSIS ini, di antaranya:

1. Menginputkan Nilai Alternatif, yang terdiri dari rata-rata ni

2. Melakukan normalisasi dari kriteria yang ada

3. Nilai Normalisasi terbobot dihitung berdasarkan setiap kriteria

4. Menampilkan matriks pemecahan masalah terbaik positif dan negatif

5. Menentukan jarak solusi dan nilai referensi

6. Terakhir memberikan keputusan akhir mana yang menjadi alternatif terbaik dari alternatif yang ada.

Berikut Tampilan halaman hasil data seleksi yang nantinya merupakan halaman dari laporan data dari pemilihan penerimaan beasiswa terbaik.

Di halaman hasil seleksi ini berupa tampilan laporan-laporan data yang sudah dimasukkan dan akan dicetak. Melalui halaman ini pimpinan dapat melihat siapa yang akan menjadi penerima beasiswa yang telah dihitung oleh sistem sesuai dengan kriteria $\mathrm{C} 1$ sampai dengan C5 yang telah diinputkan sebelumnya, kemudian sistem akan menghitung dan menghasilkan nilai terbaik melalui hasil pembobotan dan pemeringkatan. Dari hasil yang sudah dimasukkan dapat hasil tertinggi adalah Juliya Sari dengan nilai 0.75982 .

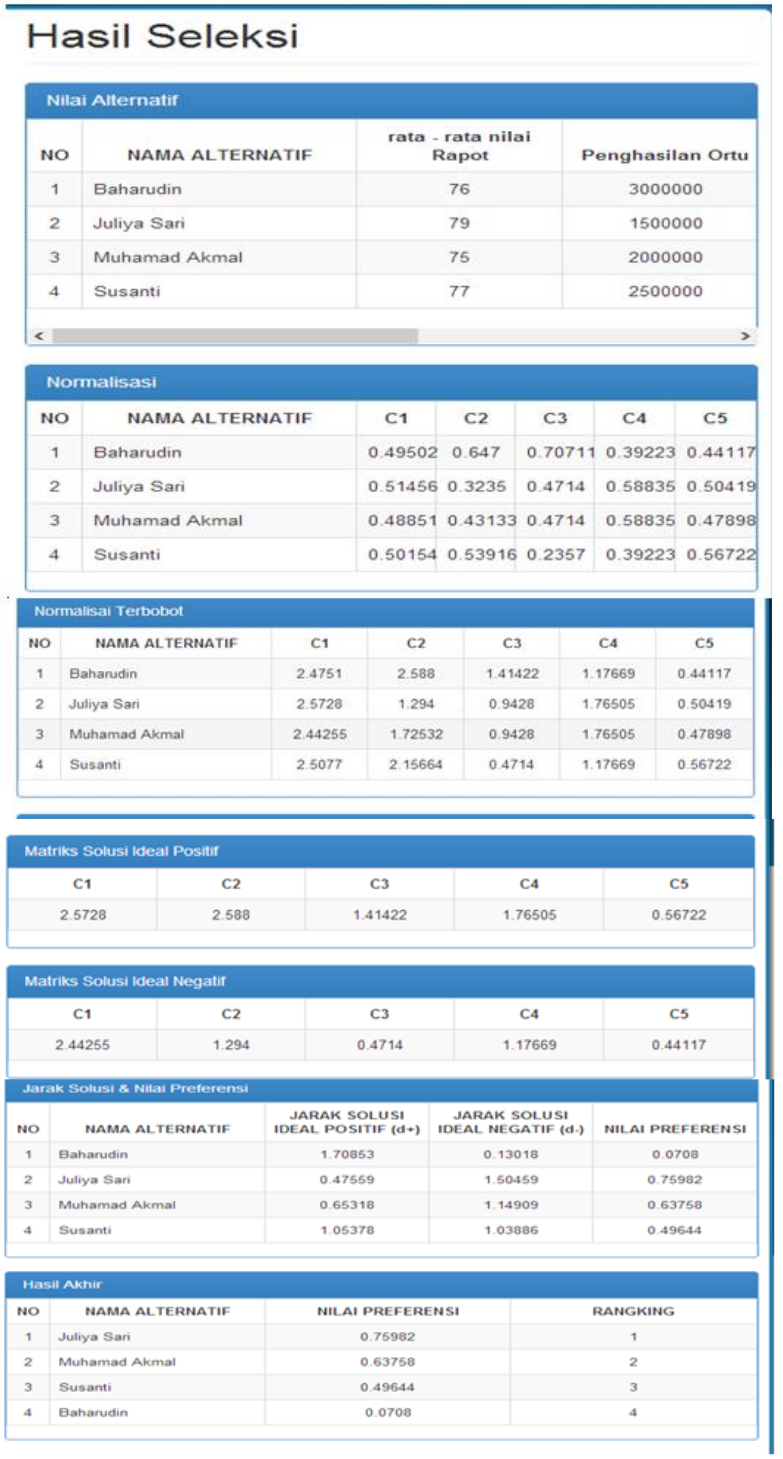

Gambar 8. Tampilan Halaman Data Hasil Seleksi

\section{Kesimpulan}

Dari penelitian yang telah dilaksanakan dan diselesaikan untuk penerapan TOPSIS method untuk, menentukan penerima beasiswa bisa disimpulkan bahwa:

1. Sistem pendukung keputusan dalam penilaian penerimaan beasiswa berbasis web ini, dapat dijadikan dasar untuk mempermudah keputusan penilaian penerimaan beasiswa dalam memilih penerimaan beasiswa terbaik setiap semesternya karena sistem akan mengolah data dan memberikan informasi dengan cepat, tepat dan konsisten kepada kepala sekolah terhadap siswa untuk menerima beasiswa terbaik yang akan diberikan.

2. Sistem pendukung keputusan dalam penilaian penerimaan beasiswa berbasis 
web, dapat mempermudah keputusan penilaian siswa terbaik SMA Negeri 2 setiap semesternya secara proporsional dengan berdasarkan hasil proses data siswa meliputi "rata -rata nila rapot, penghasilan orang tua, jumlah tanggungan orang tua, kelas, dan usia orang tua" dengan tepat dan akurat karena sistem pendukung keputusan meminimalisir kesalahan dalam proses perhitungan normalisasi data setiap semesternya.

Beberapa saran yang bisa diberikan dalam penelitian ini di antaranya yaitu:

1. Penelitian kedepannya bisa menggunakan metode pengambil keputusan yang lain agar terdapat variasi model proses dengan kasus yang sama sehingga dengan adanya perbandingan dari beberapa metode di harapkan dapat memperkuat hasil yang dikeluarkan oleh sistem agar dapat menggunakan metode dengan lebih tepat sesuai permasalahan yang ada.

2. Sistem yang telah dibangun ini diharapkan dapat dilakukan pemeliharaan secara berkala agar sistem dapat berjalan dengan baik dan maksimal.

\section{Daftar Pustaka}

Fitriana, Amelia Nur, Harliana Harliana, and Handaru Handaru. "SPK Untuk Menentukan Prestasi Akademik Siswa dengan Metode TOPSIS." Creative Information Technology Journal 2.2 (2015): 153-164.

Eniyati, Sri. "Perancangan Sistem Pengambilan Keputusan untuk Penerimaan Beasiswa dengan Metode SAW (Simple Additive Weighting)" Dinamik 16.2 (2011).

Kurniasih, Desi Leha. "Sistem pendukung keputusan pemilihan laptop dengan metode TOPSIS." Pelita Informatika: Informasi dan Informatika 3.2 (2017).

Bangkit, R., Regasari, R., \& Mahmudy, W. F. (2014). Sistem Pendukung Keputusan Pemilihan Atlet Yang Layak Masuk Tim Pencak Silat dengan Metode Simple Additive Weighting (SAW). Jurnal Mahasiswa PTNK, 4(4).

Perdana, N. G., \& Widodo, T. (2013). Sistem Pendukung Keputusan Pemberian Beasiswa Kepada Peserta Didik Baru Menggunakan Metode TOPSIS. Semantik, 3(1).

Wijaya, K., Wowor, H., \& Tulenan, V. (2015). Sistem Pendukung Keputusan Penerima Beasiswa dengan Metode Technique For Order Preference By Similarity To Ideal
Solution Di Universitas Sam Ratulangi Manado. Jurnal Teknik Informatika, 5(1).

Astuti, S., \& Muammar, M. (2017). Sistem Pendukung Keputusan Penentuan Beasiswa Menggunakan Metode Simple Additive Weighting (SAW) Studi Kasus Pada Smp Dharma Bhakti Pubian. Jurnal TAM (Technology Acceptance Model), 4, 13-18. 